Project Report

\title{
Evaluation of Disabled STEAM -Students' Education Learning Outcomes and Creativity under the UN Sustainable Development Goal: Project-Based Learning Oriented STEAM Curriculum with Micro:bit
}

\author{
Shih-Yun Lu ${ }^{1}$, Chu-Lung $\mathrm{Wu}^{2, *(1)}$ and You-Ming Huang ${ }^{3}$ \\ 1 Department of Fine Arts, National Taichung University of Education, Taichung City 403454, Taiwan; \\ lucia@mail.ntcu.edu.tw \\ 2 Department of Special Education, National Taichung University of Education, Taichung City 403454, Taiwan \\ 3 Department of Digital Content and Technology, National Taichung University of Education, \\ Taichung City 403454, Taiwan; gn02398867@gmail.com \\ * Correspondence: wulongd@mail.ntcu.edu.tw
}

Citation: Lu, S.-Y.; Wu, C.-L.; Huang, Y.-M. Evaluation of Disabled STEAM -Students' Education Learning Outcomes and Creativity under the UN Sustainable Development Goal: Project-Based Learning Oriented STEAM Curriculum with Micro:bit. Sustainability 2022, 14, 679. https:// doi.org/10.3390/su14020679

Academic Editors: Tzu-Hua Wang, Yang Teck Kenneth LIM and Jari Lavonen

Received: 24 November 2021

Accepted: 2 January 2022

Published: 8 January 2022

Publisher's Note: MDPI stays neutral with regard to jurisdictional claims in published maps and institutional affiliations.

Copyright: (C) 2022 by the authors. Licensee MDPI, Basel, Switzerland. This article is an open access article distributed under the terms and conditions of the Creative Commons Attribution (CC BY) license (https:// creativecommons.org/licenses/by/ $4.0 /)$

\begin{abstract}
This research aims to discuss the impact of the STEAM curriculum on students with learning disabilities and their learning outcomes and creativity. Teaching for creative thinking is the strategy to deliver a STEAM-structured curriculum and to reach the SDG4 targets. The content is designed in line with project-based learning (PBL), while the micro:bit and paper cutting are used as materials to support it. Methods and Procedures: The single-case research approach (A-B-M) was applied to study three students with special educational needs in primary school. The entire curriculum takes up to 10 weeks with 12 STEAM lessons with activities. The independent variable was the PBL-oriented STEAM curriculum, and the dependent variables were the learning outcomes and TTCT results of pre-tests and post-tests for creativity. There were immediate learning outcomes and retention effects found on the three participants. This paper addresses that the STEAM curriculum had a positive impact on their creativity, which gives affirmative feedback on the curriculum. Conclusion: This PBL-oriented STEAM curriculum under the SDG4 targets gave students with disabilities creativity competency and positive learning outcomes in these case studies. These teaching materials enable teachers to deliver the STEAM curriculum to students with learning disabilities.
\end{abstract}

Keywords: STEAM education; project-based learning; creativity; students with learning disabilities; sustainable development goal

\section{Introduction}

Sustainable Development Goal 4 (SDG 4) is the education goal. It aims to ensure inclusive and equitable quality education and promote lifelong learning opportunities for all.

Target 4.4: by 2030, there will be a substantial increase in the number of youth and adults who have relevant skills, including technical and vocational skills, for employment, decent jobs, and entrepreneurship.

Target 4.4: by 2030, especially in skills acquisition, beyond work-specific skills, emphasis must be placed on developing high-level cognitive and non-cognitive/transferable skills, such as problem-solving, critical thinking, creativity, teamwork, communication skills, and conflict resolution, which can be used across a range of occupational fields.

Target 4.5: by 2030, eliminate discrimination and ensure equal access to all levels of education and vocational training for the vulnerable, including persons with disabilities, especially those in vulnerable situations or other statuses; they should have access to inclusive, equitable quality education and lifelong learning opportunities. 
Science technology has developed in the 21st century, and it is crucial to integrate education with competency-based learning, creativity, and the skill of problem-solving in order to keep the country innovative and competitive. Additionally, it provides what is needed in the social economy [1]. STEM education is considered as the national strategy in the US [2], where it is implemented to cultivate interdisciplinary talents for the country [3]. Yakman [4] mentions that students would understand the culture better and appreciate aesthetics under STEAM, with the additional subject of Arts to STEM. This is achieved by building on science and mathematics, delivered to students through technology, logical thinking, and art performance [4].

According to Executive Yuan, the number of students with special educational needs in primary school has been balanced over the last 10 years. However, the number of students with learning disabilities has increased every year. It is now the first category on the list of special educational needs [5]. General students have abundant and up-to-date resources, such as self-education, core competencies, and multicultural education. On the contrary, students with special educational needs lack resources, as well as support from their families $[6,7]$.

Explicit behaviors, such as listening, speaking, reading, and writing, are the problems that students with learning disabilities encounter. This links to the issues of concentration, expression, thinking, memory, and so on [8]. Therefore, these students fall behind in STEM education [9,10]. Apart from medical support, Basham and Marino [11] state that providing appropriate and flexible learning strategies is also helpful for their learning. In view of multicultural education, leading students to find an effective or even their own learning method is the most straightforward way to improve their learning outcomes [11]. STEAM education could meet the requirement, as it provides a diverse and innovative learning environment. Students with special educational needs could discover their own learning techniques for acquiring skills.

In the past 10 years, most of the research on STEAM education concentrated on studying general students, or even the teachers or interns, rather than students with special educational needs [6,7,12-14]. Ehsan [15] reviewed 44 research papers regarding STEM and students with autism. The subjects covered were mathematics (31), science (12), technology (1), and engineering (0). Only 21 of them mentioned positive outcomes. Instead of studying STEM lesson planning and design, the 44 research papers only looked into the performance of a single skill. Given the fact that there is a lack of study on the integrated STEM education towards students with special educational needs, this study aimed to boost their cognition and stimulate their creativity with the STEAM curriculum (Science, Technology, Engineering, Arts, and Mathematics), together with skill development such as hands-on skills and problem-solving. This is relevant to SDG4 Target 4.4.

In order to design the STEAM curriculum, the researchers anticipated that utilizing PBL (project-based learning) as the teaching strategy to study students with special educational needs could improve their cognition and creativity. The structure was: (1) setting the goal, (2) designing eliciting questions, (3) plan evaluation, (4) planning, and (5) managing the process. The micro:bit by BBC was used as the material in class together with the activity of paper cutting. The result of this research could be set as an example to develop the STEAM curriculum in the future. This study aimed:

- To discuss whether there would be immediate and retention effects when applying the PBL-oriented STEAM curriculum to students with learning disabilities.

- To determine whether the PBL-oriented STEAM curriculum affects their creativity.

- To comprehend the feedback from participants after the intervention of the PBLoriented STEAM curriculum.

\subsection{STEAM Curriculum}

STEAM education is derived from STEM (Science, Technology, Engineering, and Mathematics), with the addition of Arts. It is a thematic teaching approach of interdisciplinary competencies [16]. In STEM education, students are expected to (1) participate in projects, 
(2) deliver logical reasoning, (3) cooperate, and (4) make decisions and analyze. By carrying these abilities, students are equipped for pursuing higher education and contributing to society [17]. Fan and Yu [18] are grateful to STEAM education, because through it, the productivity and economy in the United States are stimulated. Sharing the same perspective, Zollman [19] agrees that STEAM education enhances national and social development, strengthens military capability, boosts the economy, cultivates talents, and so on.

Currently, there are various theories and design models for developing the STEAM curriculum, such as project-based learning (PBL), design-based learning (DBL), and 6E Learning [20]. This study focused on students with special educational needs; hence, PBL was chosen due to its flexibility. It allows the researcher to easily amend it to meet the capability of students.

\subsection{Paper Cutting}

Another type of art, paper cutting is akin to a unique language. The more we understand, the deeper meaning will be unveiled. Li [21] identified three major categories in paper cutting: objects metaphor and symbolization, homophones, and theme.

Paper cutting is one kind of ancient folk art in China. Society and technological development diversify the culture. Recently, there is an increasing number of researchers devoted to the study related to paper cutting. Wang [22] used the brainstorming approach of creative thinking and SWOT analysis to design wallpaper. Later in 2015, Yang [23] conducted action research to discuss the impact of paper cutting lessons on juniors in primary school regarding creativity. The researcher mentions that students could understand better the form of paper cutting, as well as the folk culture. Additionally, the result of TTCT (Torrance Tests of Creative Thinking) shows improved creativity. With the help of digitalization and knowledge exchange, paper cutting could be preserved and introduced worldwide. A new type of art blended with western culture would be created.

\subsection{Creativity}

Creativity is a complex behavior of human beings that involves a wide range of aspects. It is affected by external social development, as well as educational background. Different presentational fields lead to different types of creativity [24] The study of creativity became popular when Guilford, the president of the American Psychological Association, first introduced it [25]. Rhodes [26] addressed four factors for designing a curriculum for creativity: personal character, creative process, creative product, and creative environment. These are the indicators to enable teachers to evaluate creativity presented by students. The purpose of implementing creative thinking in class is to trigger motivation. Students are encouraged to exploit their imagination and think innovatively [24]. Williams' Taxonomy by William [27] introduced a model that focuses on the cognitive and affective domain. The cognitive domain is considered the ability of divergent thinking, which includes fluency, flexibility, originality, and elaboration. The creativity assessment is needed to evaluate and review the result of the curriculum in cultivating students' creativity.

\subsection{Torrance Tests of Creative Thinking (TTCT)}

Creativity is characterized by fluent, flexible, and original thinking, which can be used as indicators to evaluate creator characteristics [28]. Despite being criticized for its lack of predictive validity and discrimination validity, TTCT remains the most common assessment of creativity in the United States and 35 other countries around the world [29]. Li [30] revised the reliability and validity of the Figural TTCT in Taiwan and reported a scorer reliability of $0.911-0.991$, a test-retest reliability of $0.401-0.724,6$ weeks after, and an alternate-form reliability of $0.598-0.951$, all of which reached the 0.05 significance level. In terms of validity, concurrent validity was established based on the creative thinking activities of the Williams Creative Thinking Test; the correlation coefficient ranged between 0.574 and 0.812 and reached the 0.05 significance level. 


\section{Material and Methods}

\subsection{Participants}

Considering the budget and manpower, participants of this study were students from a primary school located in Taichung City, Taiwan. There were a total of 3 students who needed to meet the following criteria:

(a) Students are identified as those who have learning disabilities and are arranged in a resource class.

(b) Students attend added and pull-out lessons while in the resource class.

(c) Students understand basic instruction and can complete daily living activities independently without having problems with sight, hearing, or fine movement. For example, they can reach a specific book and take it, or clean a desk.

(d) Students with no experience of STEAM.

Once the students were selected, the researcher explained the process of the experimental teaching and risk to their parents. Once they consented, the students officially participated in the study with fake names for privacy.

The details of the three participants can be found in Table 1.

Table 1. Details of the three participants.

\begin{tabular}{cccc}
\hline Name & Ama & Bella & Candy \\
\hline Grade (age) & 6th grade (12 years old) & 6th grade (12 years old) & 6th grade (12 years old) \\
Gender & Female & Female & Female \\
& WISC-IV & WISC-IV & WISC-IV \\
& Overall 72 & Overall 72 & Overall 77 \\
Test & Verbal Comprehension 83 & Verbal Comprehension 79 & Verbal Comprehension 85 \\
& Perceptual Reasoning 63 & Perceptual Reasoning 78 & Perceptual Reasoning 77 \\
& Working Memory 89 & Working Memory 75 & Working Memory 94 \\
& Processing Speed 70 & Processing Speed 65 & Processing Speed 73 \\
& Pull-out lessons for Chinese & Pull-out lessons for Chinese & Pull-out lessons for Chinese \\
Special education & and Mathematics & and Mathematics & and Mathematics \\
& Active in learning. Interested & Active in learning. Interested & Active in learning. Sensible in \\
& in learning with Q\&A. & in practical operation but & images. Knows how to take \\
& Actively discusses with peers & easily distracted by the & notes in class strategically. \\
Learning habit & if there is any doubt. & external environment. & No \\
& No & No &
\end{tabular}

\subsection{Independent Variable}

The independent variable was PBL-oriented STEAM. The students were asked to complete 12 lessons, starting from easy to difficult. There were 2 lessons per week of $40 \mathrm{~min}$ each. The teacher amended the content of the lessons if needed based on the students performance.

\section{PBL Curriculum Design Process}

Setting a Goal and Planning

Arts and Technology are the core subjects of the curriculum. Together with Mathematics, Engineering, and Science, students complete tasks to create their artworks. After the STEAM curriculum design, paper cutting is more than just a skill-based activity-it is a part of the arts training included in the STEAM curriculum that can enhance the demonstration of creativity. The analysis of content and teaching aims are explained in the following sections.

Designing "Eliciting Questions"

1. How can you apply technology to paper cutting?

2. How can you use sounds and movement to control the light?

3. How can you control the artwork of paper cutting? 


\section{Curriculum Assessment}

The assessment enables the teacher to understand students' learning progress and review the curriculum to decide if amendments are needed.

Project Planning

There are 4 teaching activities designed based on Science, Technology, Engineering, Mathematics, and Arts (Figure 1).

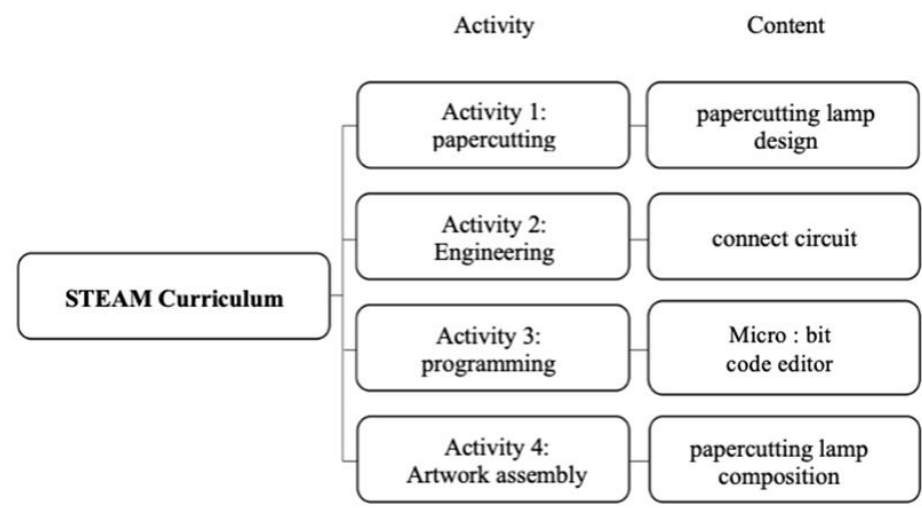

Figure 1. Teaching plan.

Process Management

The teacher evaluates upon the completion of each activity and revises the curriculum to be suitable for the students with special educational needs.

\subsection{Dependent Variables and Evaluation}

Learning outcomes and creativity demonstrated after the STEAM curriculum were considered the dependent variables. The former was reviewed by conducting an evaluation, in which the teacher was able to check each step. There were a total of 16 steps in the evaluation form. The more tasks the students performed during the activities, the better the performance they delivered. Students received 2 points for each step they completed individually, 1 point with the assistance of the teacher, and 0 points if they failed.

TTCT was used to review creativity before and after the completion of the STEAM curriculum. There were 3 activities to check 5 creative characteristics: fluency, originality, title, elaboration, and openness.

\subsection{Experiment Design}

This analysis is built on the withdrawal design of the single-case approach to discuss the learning outcomes and creativity of the 3 participants after participating in the PBLoriented STEAM curriculum. This study employed a single-subject withdrawal design as the research framework because of the small sample size and large individual differences, which renders the implementation of quantitative research difficult. Single-subject research - a quantitative experimental design commonly used in the event of a limited sample size-comprises baseline, treatment, and maintenance phases with repeated measurements of causality. The proposed intervention was found to exhibit favorable reliability and validity [20].

\subsection{Procedures}

The researcher explained the following information before the experimental teaching started: (1) It is voluntary to participate in the study. There will not be any consequences for leaving anytime during the research. (2) The result of the evaluation (accuracy) is only for research purposes. It will not affect their impression at school, nor their academic record. (3) The lessons will be recorded. If the participants feel uncomfortable, they can ask to terminate the curriculum. 


\subsubsection{Baseline Stage}

The baseline measure aimed to evaluate the initial STEAM performance without the students being trained or taught. In line with the withdrawal design of single-case approach, there were 3 tests at this stage. The researcher collected data using the STEAM evaluation form and then analyzed it with TTCT for the pre-test. No clues were given by the researchers or observers to the participants when completing the tasks. When three successive data points were stable in the baseline trend, the STEAM curriculum began.

\subsubsection{Teaching Intervention Stage}

At this stage, participants were asked to take part in at least 6 lessons. Lessons lasted for 40 minutes, with the first 20 minutes for demonstration and practice. The rest of the time, the activities were assessed. Learning effect was evaluated after each intervention to assess its immediate effect. The researcher and observer were not allowed to hint.

\subsubsection{Retention Stage}

Two weeks after the teaching intervention, the students completed the evaluation for learning outcomes and retention. There was no teaching involved during the interval. As was done in the baseline stage, no clue was given. However, the participants were encouraged verbally.

\subsection{Reliability}

An inter-observer agreement (IOA) was conducted for reliability. There was another observer evaluating the results on the 3 participants at 3 stages, and which were then compared with the original data. The calculation was based on the below formula.

$$
\mathrm{IOA}=\frac{\text { the amout of consistency }}{\text { the amount of consistency and inconsistency }} \times 100 \%
$$

The result of all the participants at all stages was $100 \%$.

In terms of the consistency in the progress, the external observer reviewed the video taken 3 times and reported any discrepancies. The result of this evaluation was $100 \%$.

\subsection{Feedback}

The participants were interviewed after the experimental teaching in order to receive their feedback. Information was collected by inquiring the participant's experience during the curriculum. The questions were: (1) Do you like this teaching method? (2) Do you feel your creativity has improved? (3) What have you learned from the curriculum? (4) What are the differences compared with the general curriculum? (5) What impressed you the most? (6) What is the least interesting part? (7) What is your overall feedback?

\subsection{Analysis}

Visual Analysis was chosen for data analysis within and between stages. The results indicate the stability, trend, and learning outcomes individually and in a small group.

\section{Results}

All the participants obtained immediate effects after the curriculum. The students were able to make code for the micro:bit independently (Figure 2), and their works of paper cutting are shown as Figure 3. Looking into the accuracy made, the points increased from an average of 2.4 in the baseline stage to 16.8 in the intervention stage. The data in the retention stage are the highest at 26.8. Hence, this curriculum had an immediate as well as retention effect on the students performing in STEAM education (Figures 4-6). 


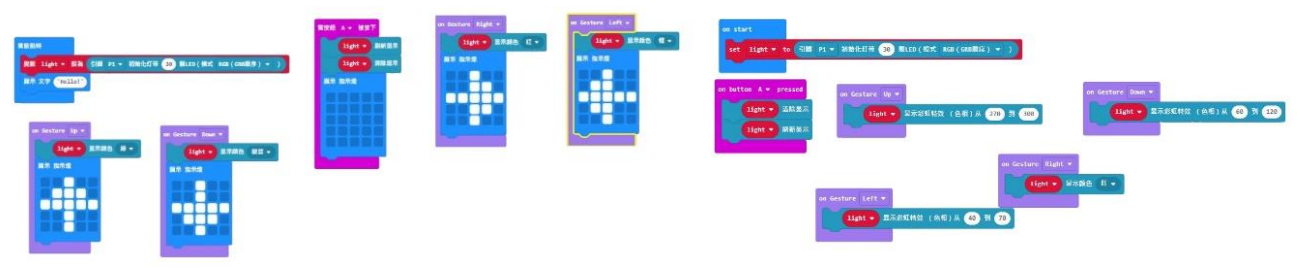

Figure 2. Making code for the micro:bit.
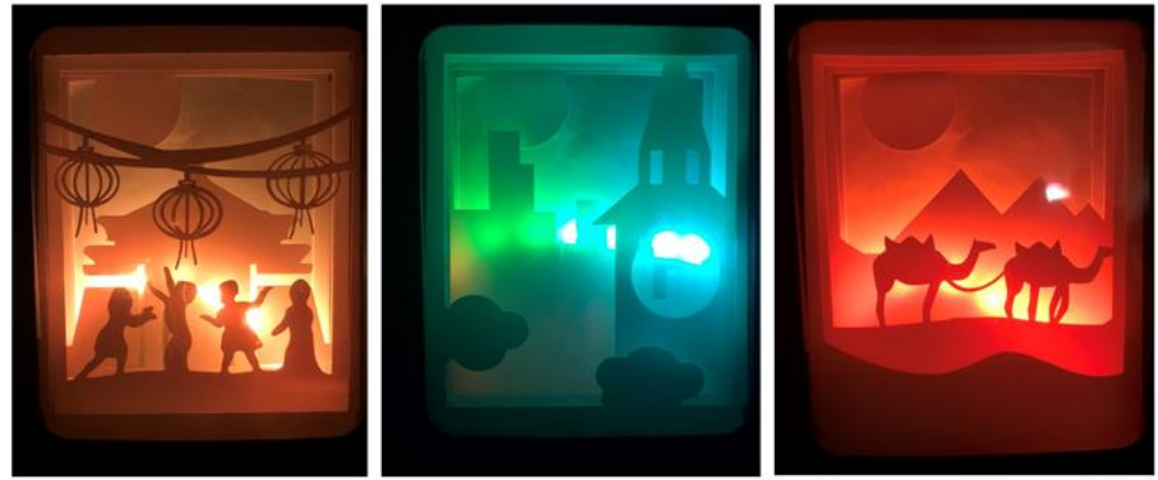

Figure 3. Students' work.

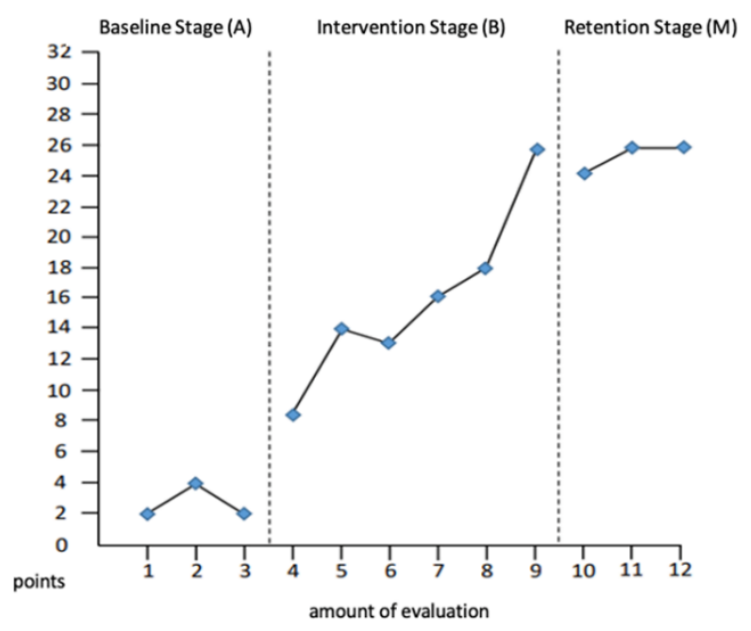

Figure 4. Evaluation of STEAM curriculum (Ama).

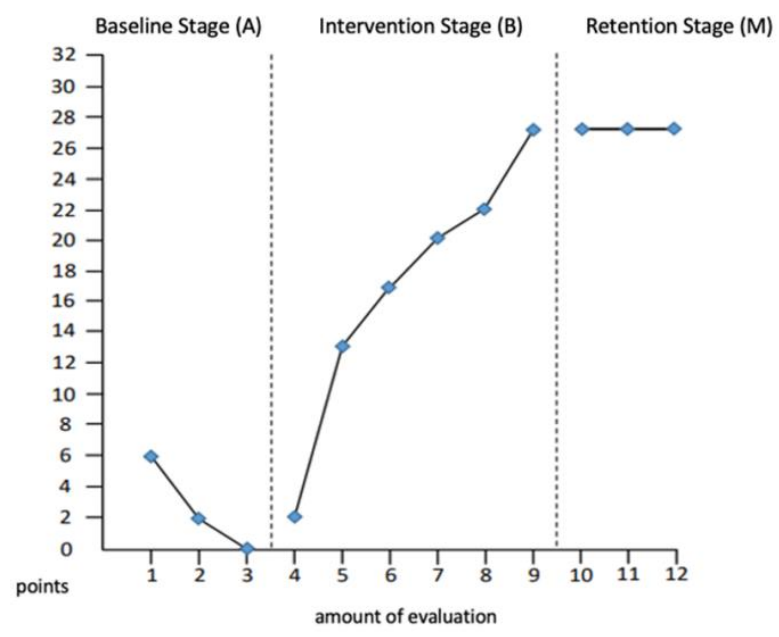

Figure 5. Evaluation of STEAM curriculum (Bella). 




Figure 6. Evaluation of STEAM curriculum (Candy).

\subsection{Ama}

The data in the baseline stage are average performance (2.76), trend stability $(100 \%)$, and while in the intervention stage, both are at $100 \%$. The trend is stable at the first stage before moving to the next. It keeps moving positively and steadily (average accuracy $=15.57$, range: $8-26$, variation +18$)$. As shown in the retention stage $(\mathrm{M})$, both performance and trend stability on the STEAM curriculum are steady. Overall, the data in the retention stages are the highest (25.33). It evinces that after the STEAM curriculum, Ama managed to keep her performance.

Moreover, the variation increases by 6 points from stages $A$ to $B$. The trend reflects positively with performance $(+13)$ and overlap percentage $(0 \%)$. It indicates that the STEAM curriculum affected Ama immediately and positively. The variation from B to $\mathrm{M}$ is -2 , together with average performance $(+9.66)$ and overlap percentage $(100 \%)$. It demonstrates that Ama is capable of retaining her performance.

\subsection{Bella}

Looking at the diagram of Bella, the trend goes down before the intervention stage. However, it goes up directly and steadily in stage B (stage variation $=2$, overlap percentage $=0 \%$, average accuracy $=16.83$, range: $2-27$ ). The data show an immediate effect. Concerning $\mathrm{M}$, the performance on STEAM and trend stability are balanced. The variation from $B$ to $M$ is +0 (overlap percentage $=100 \%$ ). It indicates that Bella could retain her problem-solving ability after participating in the STEAM curriculum.

\subsection{Candy}

On the diagram of Candy, the trend keeps steady before stage B (stage variation +4 , overlap percentage $=0$ ). In stage $B$, the trend moves positively. The average accuracy is 18 (range: 6-28). This result evinces that the teaching intervention affected Candy immediately. The variation from B to $\mathrm{M}$ is 0 (overlap percentage $100 \%$, average performance $=28$ ). Based on this result, Candy could keep her performance after the curriculum.

\subsection{The Impact of STEAM to Creativity}

This study adopted the revised TTCT by Li [30] to discuss creativity before and after taking the STEAM curriculum. There were a total of two tests to understand how creativity changes among the participants. The pre-test was completed before the curriculum, while the post-test was completed after the curriculum in the form of an interview (Table 2). 
Table 2. Revised TTCT results (pre-test and post-test).

\begin{tabular}{|c|c|c|c|c|c|c|c|}
\hline \multicolumn{2}{|c|}{ Participants } & \multicolumn{2}{|c|}{ Ama } & \multicolumn{2}{|c|}{ Bella } & \multicolumn{2}{|c|}{ Candy } \\
\hline Creativity & Result & Score & $\begin{array}{c}\text { Percentile } \\
\text { Rank }\end{array}$ & Score & $\begin{array}{c}\text { Percentile } \\
\text { Rank }\end{array}$ & Score & $\begin{array}{c}\text { Percentile } \\
\text { Rank }\end{array}$ \\
\hline \multirow{2}{*}{ Flexibility } & Pre-test & 65 & 4 & 65 & 4 & 78 & 14 \\
\hline & Post-test & 89 & 30 & 78 & 14 & 99 & 49 \\
\hline \multirow{2}{*}{ Originality } & Pre-test & 73 & 10 & 70 & 8 & 78 & 15 \\
\hline & Post-test & 93 & 38 & 78 & 15 & 86 & 25 \\
\hline \multirow{2}{*}{ Title } & Pre-test & 61 & 13 & 64 & 19 & 55 & 8 \\
\hline & Post-test & 69 & 27 & 73 & 36 & 69 & 27 \\
\hline \multirow{2}{*}{ Elaboration } & Pre-test & 67 & 9 & 76 & 19 & 76 & 19 \\
\hline & Post-test & 76 & 19 & 87 & 32 & 87 & 32 \\
\hline \multirow{2}{*}{ Openness } & Pre-test & 74 & 11 & 73 & 10 & 78 & 15 \\
\hline & Post-test & 89 & 31 & 89 & 31 & 89 & 31 \\
\hline \multirow{2}{*}{ Mean } & Pre-test & 68 & 3 & 70 & 3 & 73 & 5 \\
\hline & Post-test & 83 & 15 & 81 & 12 & 86 & 20 \\
\hline
\end{tabular}

Overall, the three participants changed positively after taking the STEAM curriculum. The data are: Ama (mean +15 , percentile rank +12$)$, Bella (mean +11 , percentile rank +19$)$, and Candy (mean +13 , percentile rank +1$)$. There was a significant impact among the three participants on flexibility, originality, and openness, rather than title and elaboration.

\subsection{Process of Learning and Improvement}

\subsubsection{Positive Feedback towards STEAM Curriculum}

According to the information collected in the interviews, the three participants are open to an interdisciplinary curriculum. They commented that it is intriguing and diverse, as they could learn about circuit boards and programming. They are also willing to try new things after taking the STEAM curriculum.

Instead of lectures, they prefer lessons with hands-on activities. The latter could trigger their motivation and increase their interests.

\subsubsection{Self-Assurance and Confidence Are Improved}

The participants mentioned that the curriculum improves their problem-solving ability, which makes them feel more confident and helps them stay calm when encountering obstacles. They are motivated throughout the class. They believe that they could apply creativity in other areas of learning. On top of that, the STEAM curriculum changes the way they think and affirmatively changes their self-assurance.

\section{Discussion}

\subsection{Discovery}

This research aim at discussing whether the PBL-oriented STEAM curriculum could positively affect the learning outcomes and creativity of students with learning disabilities. The result is affirmative. There were immediate and retention effects found among the three participants. This echoes the research performed by Hart and Whalon [31] showing that the appropriate strategy and teaching methods could improve learning in students with special educational needs in STEAM learning. Additionally, the three participants changed their behavior in class.

Ama started to think and try to find solutions for the tasks. It helped her to obtain more points in the evaluation. On the other hand, Bella managed to stabilize her emotions when the curriculum started. She did not give up as many times as she used to. As for Candy, she was able to use the knowledge she learned in class to solve the problems. These changes relate to the practical teaching strategy of this curriculum. This is in line with the suggestion made by Wright et al. [32]. 


\subsection{Creativity}

When the curriculum began, the creativity among the three participants started to change. Due to the differences in learning ability and thinking processes, the results were different for each student.

Ama improved the most in flexibility, originality, and openness. Originality and openness were demonstrated when she designed the background of her paper cutting, and used the hand gesture to control LEDs. The ability to incorporate various sceneries to the background and using hand movements to enhance it indicates flexibility.

Bella was able to draw several shapes, such as polygons, and use different types of lines, such as dotted lines, to reflect on the background of her paper cutting. In this case, Bella developed more in terms of openness.

As for Candy, she started to use shapes and lines to design her artwork. Other than that, she took notes of words and phrases heard in class and reviewed them afterward. In this case, Candy expanded more in flexibility and title.

\subsection{UN Agenda 4.4}

Sustainable Development Goal 4 (SDG 4) is the education goal that aims to "ensure inclusive and equitable quality education and promote lifelong learning opportunities for all". The core connotations of SDG 4 are as follows: all people, irrespective of socioeconomic background, place of residence, sex, and ethnicity, should have equal access to educational resources and quality education, thereby ensuring that everyone's talent and potential can be fully realized. In addition, the UN hopes to cultivate lifelong learning skills to realize the philosophy of and achieve a lifestyle of sustainable development. Focusing on quality education for students with special needs, this study aligns with Target 4.4 of SDG 4- "By 2030, substantially increase the number of youth and adults who have relevant skills, including technical and vocational skills, for employment, decent jobs and entrepreneurship." Specifically, the UN aims to ensure equal access to all levels of education and vocational training for the vulnerable, including persons with disabilities and socially / financially vulnerable children. The proposed curriculum can enhance information technology skills, artistic ability, and technical and vocational skills among students with special needs.

\section{Conclusions}

This paper addresses that the PBL-oriented STEAM curriculum benefits students with learning disabilities. The results of this study indicate immediate and retention effects. STEAM is an interdisciplinary curriculum that might be difficult in terms of hands-on courses. The design of the STEAM course in favor of participants with learning disabilities had a positive outcome. They gained the concept of STEAM, which may cultivate their creativity, resulting in the ability to impact their future development, as well as extend their problem-solving ability with confidence, which is relevant in this research of how to reach SDG4 Target 4.4. Researchers should consider a wider range of participants and thoroughly understand the learning outcomes and creativity competency results of implementing STEAM. Students' interests, academic knowledge, and life experiences should be taken into account in developing the curriculum. In addition to the PBL discussed in this research, researchers should also consider various models of STEAM curricula tailored to their needs.

From the perspective of clinical teaching, this study proposed a curriculum design model for teachers to follow. The result is attributable to package teaching, and that implies the effect of a single factor is infeasible.

Author Contributions: Conceptualization, S.-Y.L.; methodology, C.-L.W.; software, Y.-M.H.; validation, S.-Y.L., C.-L.W., and Y.-M.H.; formal analysis, Y.-M.H.; investigation, Y.-M.H.; resources, S.-Y.L.; data curation, Y.-M.H.; writing-original draft preparation, Y.-M.H.; writing—review and editing, S.-Y.L.; visualization, S.-Y.L.; supervision, S.-Y.L.; project administration, S.-Y.L.; funding acquisition, S.-Y.L. All authors have read and agreed to the published version of the manuscript. 
Funding: This research received no external funding.

Institutional Review Board Statement: Not applicable.

Informed Consent Statement: Not applicable.

Data Availability Statement: Not applicable.

Acknowledgments: We would like to express our special thanks to the students who participated in this study. We are very grateful to them.

Conflicts of Interest: The authors declare no conflict of interest.

\section{References}

1. Chang, J.C.; Lin, K.M. A review of the U.S. STEM education-the experience and praxis of the state of Ohio. J. Technol. Hum. Educ. Q. 2019, 5, 1-25. [CrossRef]

2. Chong, B.C.; Chang, L.F. The role and enlightenment of the "change equation" in the reform of American STEM education. China Audio-visual Educ. 2014, 4, 18-86.

3. The White House. Preparing a 21st Century Workforce-Science, Technology, Engineering, and Mathematics (STEM) Education in the 2014. Budget. Available online: http:/ / www.whitehouse.gov / ostp (accessed on 24 August 2018).

4. Yakman, G. STEAM Education: An overview of creating a model of integrative education. Pupil's Attitudes Toward Technology 2008, 19, 335-358.

5. Ministry of Education. 109 Special Education Statistical Annual Report; Ministry of Education: Taipei City, Taiwan, 2020.

6. Chang, K.H. The Number of Special Education Students Has Increased by 10,000 in the Past Ten Years. Scholars Call for Increased Parental Education. United News Network. Available online: https://udn.com/news/story/6885/4523218 (accessed on 21 January 2021).

7. Chang, L.C. Cultivate In-Service Teachers to Use 6E Teaching Model for STEAM Course Design and Team teaching. Master's Thesis, Department of Natural Science Education, National Taipei University of Education, Taipei City, Taiwan, 2020.

8. Montague, M.; Enders, C.; Dietz, S. Effects of cognitive strategy instruction on math problem solving of middle school students with learning disabilities. Learn. Disabilities. Q. 2011, 34, 262-272. [CrossRef]

9. Aronin, S.; Floyd, K.K. Using an iPad in inclusive preschool classrooms to introduce STEM concepts. Teach. Except. Child. 2013, 45, 34-39. [CrossRef]

10. National Center for Education Statistics. National Assessment of Educational Progress (NAEP) 2011 Science Assessments; United States Department of Education: Washington, DC, USA, 2013.

11. Basham, J.D.; Marino, M.T. Understanding STEM education and supporting students through universal design for learning. Teach. Except. Child. 2013, 45, 8-15. [CrossRef]

12. Syu, J.Y. The Investigation of the Creativity in STEAM Curriculum for the Senior Year Grades Elementary School- A Case Study of the Interactive Lamp by Paper Carving with Micro: Bit. Master's Thesis, Department of Digital Content Technology, National Taichung University of Education, Taichung City, Taiwan, 2019.

13. Boakes, N.J. Cultivating design thinking of middle school girls through an origami STEAM project. J. STEM Educ. Res. 2020, 3 , 259-278. [CrossRef]

14. Danah, H. Creating STEAM with design thinking: Beyond STEM and arts integration. STEAM J. 2017, 3, 11.

15. Ehsan, H.; Rispoli, M.; Lory, C.; Gregori, E. A systematic review of STEM instruction with students with autism spectrum disorders. Rev. J. Autism Dev Disord. 2018, 5, 1-22. [CrossRef]

16. Fu, Y.W. A Professor's Reflection on the Progress of Integrating 'STEAM Course Design' into the 'Teaching Materials and Methods of Science and Life Technology in Elementary School' Course. Master's Thesis, Department of Natural Science Education, National Taipei University of Education, Taipei City, Taiwan, 2020.

17. Maryland STEM: Innovation Today to Meet Tomorrow's Global Challenges; Maryland State Department of Education: Baltimore, MD, USA, 2012.

18. Zollman, A. Learning for STEM literacy: STEM literacy for learning. School Sci. Math. 2012, 112, 12-19. [CrossRef]

19. Zheng, W. China STEAM Education Development Report. Science Press: Beijing, China, 2017.

20. Ledford, J.R.; Lane, J.D.; Gast, D.L. Dependent variables, measurement, reliability. In Single Case Research Methodology, 3rd ed.; Ledford, J.R., Gast, D.L., Eds.; Routledge: New York, NY, USA, 2018.

21. Li, X.X. Paper Cut Art; Jiaotong University Press: Xi'an, China, 2005; ISBN 7560518656.

22. Wang, Y.D. The Creation and Research of Auspicious Creative Paper Cutting Wall Stickers Applied to the Interior Decoration. Master's Thesis, National Dong Hwa University, Hualien County, Taiwan, 2014.

23. Yang, B.F. An Action Research on the Development of School Children's Creativity through Paper Cutting Course - A Case Research on the Second Grade Students of the Elementary School. Master's Thesis, Huafan University, New Taipei City, Taiwan, 2015.

24. Runco, M.A.; Sakamoto, S.O. Experimental studies of creativity. In Handbook of Creativity; Sternberg, R.J., Ed.; Cambridge University Press: Cambridge, UK, 1999; pp. 62-92. [CrossRef] 
25. Hong, C.L. A Study of the Application of STEAM in the Insect Pop-up Books Curriculum Design. Master's Thesis, National Taipei University of Education, Taipei City, Taiwan, 2020.

26. Rhodes, M. An analysis of creativity. Phi Delta Kappan. 1961, 42, 305-310.

27. Mao, L.Y.; Guo, Y.W.; Chen, L.; Lin, X.T. Creativity Research; Psychological Press: Taipei, Taiwan, 2000.

28. Wallach, M.A.; Torrance, E.P. Torrance Tests of Creative Thinking: Norms - Technical Manual. Am. Educ. Res. J. 1968, 5, $272-281$. [CrossRef]

29. Millar, G.W. The Torrance Kids at Mid-Life: Selected Case Studies of Creative Behavior; Ablex Publishing: Westport, CT, USA, 2002.

30. Li, I.M. Torrance Tests of Creative Thinking in Graphs; Psychological Press: Taipei, Taiwan, 2006.

31. Williams, F.E. Classroom Ideas for Encouraging Thinking and Feeling, 2nd ed.; D.O.K: New York, NY, USA, 1970.

32. Hart, J.E.; Whalon, K.J. Using video self-modeling via iPads to increase academic responding of an adolescent with autism spectrum disorder and intellectual disability. Educ. Training Autism Dev. Disabil. 2012, 47, 438-446. 